\title{
Mobile Assisted Learning for Self-Directed Learning Development at Technical University: SWOT Analysis
}

\author{
Nataliia Saienko ${ }^{1}$, Yuliana Lavrysh ${ }^{2, *}$ \\ ${ }^{1}$ Faculty of Linguistics, National Technical University of Ukraine "Igor Sikorsky Kyiv Polytechnic University”, Ukraine \\ ${ }^{2}$ Department of English for Engineering, Faculty of Linguistics, National Technical University of Ukraine "Igor Sikorsky Kyiv \\ Polytechnic University", Ukraine
}

Received Jnauary 15, 2020; Revised March 18, 2020; Accepted March 28, 2020

Copyright $\odot 2020$ by authors, all rights reserved. Authors agree that this article remains permanently open access under the terms of the Creative Commons Attribution License 4.0 International License

\begin{abstract}
The aim of the paper is to identify strengths, weaknesses, opportunities, and threats (SWOT) of self-directed learning (SDL) supported by mobile-assisted technologies integrated into English for Specific Purposes course at university. Teachers cannot prepare students for all challenges of the modern world; therefore, students need skills of self-education to keep updated. SDL skills are crucial for today's learners but, as they include such features as ownership for learning, self-managing, self-reflection and extension of learning, SDL skills should be explained and trained by teachers-facilitators. The goal of our study was to carry out a SWOT analysis of the technology-enhanced SDL process from teachers' and students' points of view. This kind of analysis will allow identifying common and different issues that participants of the study encounter in the process of SDL. Therefore, we carried out a qualitative study with questionnaires to perform a SWOT analysis and to identify problematic issues. Comparing the results, we found out that students and teachers identified mostly the same strengths and opportunities, whereas weaknesses and threats were different and required immediate meaningful solutions. Regarding educational technologies' impact, we observed that their integration also caused challenges for teachers to cope with. This study evidenced that technologies are a powerful tool to develop SDL skills and we developed some practical recommendations on how to avoid threats and eliminate weaknesses of SDL skills formation assisted by technologies. We also suggest some mobile-assisted technologies for the enhancement of SDL skills.
\end{abstract}

$\begin{array}{llrr}\text { Keywords } & \text { Self-Directed } & \text { Learning, } & \text { Educational } \\ \text { Technologies, } & \text { Self-Reflection, } & \text { SWOT } & \text { Analysis, } \\ \text { Information Assessment } & & \end{array}$
Information Assessment

\section{Introduction}

The idea of self-directed learning is not new as it is associated with learner autonomy, but it has been recently differentiated and gained more attention over the last decade. Self-initiated and directed learning is completely different from the learning that is regulated and generated from the outside. In terms of educational freedom, such learning is turned into the opportunity and choice matter that is supported by students' intrinsic motivation and curiosity. Self-directed learning (SDL) is a strategy that empowers learners with a responsibility for their learning process. The strategy includes learning needs identification, setting learning goals, and selection of learning strategies, techniques, and e-learning outcomes evaluation. "Learning what to learn, how to learn it, and how to decide if one has learned something well enough are all in the hands of learners" [1]. Providing the opportunity to learn according to students' academic needs, educators create the environment of creativity and motivation not typically for a 'one-size-fits-all' format of the education.

Teachers should admit that they are not a unique source of knowledge any more and students' educational needs go beyond rules and information that can be suggested by teachers can be found on the Internet. Students require skills that will help them thrive in the continuously changing reality. Standards-based teacher-led higher education is still about teaching to the next level in education and preparing for tests taking. Meanwhile, our goal should be to enhance a wish to learn and to provide students with learning strategies for lifelong learning.

The global labor market changes caused by the implementation of technologies contribute to the creation of new highly valued jobs that are envisioned now. Moreover, employers are seeking for self-directed specialists who are ready to develop their skills and knowledge continuously. And taking into account this fact, 
we, as teachers, can state that future successful careers depend on such vital skill as life long learning that happens mainly in a self-directed mode that is mostly provided through mobile devices and online resources. However, mobile-assisted learning is not just the transfer of educational materials to a device; it is an entire reinterpretation of the materials and mode of their delivery. In the process of shifting to mobile pedagogy, it is crucial to remember that this transformation is more about collaboration, communication, and self-development, not about just uploading the content.

\subsection{Research Goal}

Thus, we decided to focus our research on the strategies for the facilitation of mentioned skill development through technology-enhanced classes. In our opinion, modern educational technologies, platforms and on-line resources integrated into the learning process, impact teacher's mode of educational materials and strategies delivering. We are teachers of English for Engineering at Igor Sikorsky Kyiv Polytechnic Institute and our subject implies not only equipping students with the hard skills of the language competence but with such soft skills as self-initiated or self-directed learning. We often integrate mobile-assisted learning strategies, as the most widely spread among the youth, into the language teaching process to develop the skills of self-directed learning and motivate a student to accept the concept of lifelong learning. Therefore, the present study intends to consider the influence and effect of mobile-assisted learning on self-directed learning skills formation during classes of the English language at a technical university. So, our research was designed to achieve the following objectives:

- implement mobile learning strategies to develop self-directed learning skill;

- verify the results of the suggested strategies framework using the methods of SWOT analysis;

- share some practical recommendations on how to prevent or eradicate weaknesses or threats.

The findings of the study could empower teachers as well as students with knowledge on how to become successful lifelong learners and not to be lost in the great variety of Internet resources. The importance of our study lies in the fact that if educators want to equip their students with current must-have skills of self-development, teachers should be aware of strategies on developing and practicing these skills inside and outside the classroom using educational tools that are interesting and understandable for students.

\subsection{Theoretical Background}

Self-directed learning (SDL) is considered to be a subfield of the andragogy and results in meaningful research of Knowles, Holten, and Swanson [2] who claimed that SDL was one of the features of adult psychological maturity. However, additional research has appeared due to current increasing social demands and technological challenges faced by educators and practitioners. The key difference in modern studies on SDL is that they are more focusing on the impact of technologies on SDL than on the psychological side of the is sue $[3,4]$. The influence of technology on the development of self-directed learning is described in the research of Tan [5] where the author states that digital tools allow students to get immediate feedback, to identify learning needs while reflecting on mistakes and learning how to set goals Howland et al. [6] highlighted that technologies provide deep substantial learning because technologies make the learning process active, dynamic, authentic, constructive, and cooperative.

The holistic approach to study the issues is proposed in the research of Kim et al. [7] who see the distinctive nature of SDL through the combination of such characteristics as flexibility (freedom of choice and designing own learning); learner ownership; learner empowerment (access to meaningful resources, content, and technologies). It is justified by the fact that students are involved in self-learning through online or mobile educational technologies which call for an advanced level of self-directed learn ing skill, for example, crit ical as sess ment of the appropriate technology or an educational resource. This issue led to the research on the nature of skills that are necessary to reach the learning outcome and not to be lost in the Internet space. Thus, Doyle [8] identified a number of important personalskills students should master:

- $\quad$ finding and evaluating quality sources of information;

- identifying important information in quality sources;

- $\quad$ organizing information in meaningful ways;

- $\quad$ writing reports and papers;

- managing time;

- $\quad$ remembering what has been learned;

- using problem-solving systems ;

- monitoring own learning (meta-cognition).

In order to develop those skills, students need knowledge on how to organize their learning towards the self-directed approach and how to reflect on results of self-directed learning. Researchers Ambrose, Bridges, DiPietro, Lovett and Norman [9] developed a five-component meta-cognitive model as an organizational tool for the efficient self-d irected learn ing implementation:

- $\quad$ assess the task's goals and constraints;

- identify personalstrengths and weaknesses;

- create a strategic plan of learning;

- monitor the progress while putting the plan into practice;

- reflect on the learning results with the following adjustment of strategies.

However, it is not enough to follow all steps of the model to become a self-directed learner. This learning 
approach generates personality changes that are critical to achieve learn ing goals. The wide range of literature sources suggests various views on what personal traits and abilities are important for a self-directed learner. Among such specific personal traits, Wang and Holcombe [10] and Zimmerman [11] single out intrinsic motivation, persistence, determination, responsibility, and curiosity. This idea is supported by Du Toit-Brits and Van Zyl [12] but they claim that the extent of these traits development depends on the degree of necessity, professional or general focus of learning and quality of educational technology or material to be learned. A survey was conducted by Grover et al. [13] demonstrated that not only traits but personal abilities such as self-regulation, self-management, and control over the process were vital for the process of self-directed learning. An empirical study of Tekkol and Demirel [14] has evidenced that "openness" is the most essential and natural feature related to self-directed learning whereas self-monitoring is the ability that should be trained more.

Having analy zed a variety of research on SDL, we have noticed that most of the models of SDL involve three key components: context (skills and abilities), personal features (motivation, self-reflection, autonomy, responsibility) and the learning process organization. So me previous research declared other dimensions. For instance, Garrison [15] suggested three components: motivation, responsibility, and self-control. Candy, Crebert, and O'Leary [16] identified four components: learner's autonomy, self-control, self-management and searching for opportunities. However, only recent research suggests the combination of context, personal traits development, and educational technologies integration into the general model of SDL [17]. These findings evidence the complexity of SDL for a learner to gain this skill as well as for teachers to develop it. With this in mind, our research touches strengths, weaknesses, opportunities, and threats (SWOT) for teachers and students.

\section{Materials and Methods}

\subsection{Research Design}

The present study focuses on the analysis of strengths, weaknesses, opportunities, and threats of SDL formation by means of mobile educational technologies integrated into the educational process. We consider SWOT analysis as a powerful tool to study the perception of students and teachers in the SDL formation process and its outcomes. This research method helps us identify both internal (strengths and weaknesses) and external (opportunities and threats) factors [18] of the process. Once we identify these factors, we are able to develop strategies to find solutions to threats and weaknesses as well as improvement for strengths.
In order to conduct our study, we chose the qualitative research method as it reviews the personal needs and values of the study participants, suggests collaboration among participants and allows the data interpretation with the following creation of agenda for changes [19]. The primary aims of the survey were to establish the awareness of the SDL as a pedagogical phenomenon by exp loration of participants' awareness and attitude towards SDL and to define the internal and external factors that enhance or prevent the development of SDL. One of the benefits of the qualitative method is that it implies the holistic approach to the researched issue taking into account multiple perspectives, challenges, and opportunities of the phenomenon.

\subsection{Participants}

The participants of the study were 102 fourth-year students. The distribution of the nu mber of participants was as follows: 50 students majoring in Mechanical Engineering, 25 students majoring in Chemical Engineering, 27 students majoring in Telecommunication Systems and 35 teachers (24 teachers of English for Engineering and 9 teachers of field-related courses) who integrated SDL assisted with mobile educational technologies into their courses.. We engaged fourth-year students because it was the last year of their bachelor study and they were fully aware that the future successful career would require skills of SDL without teachers' assistance. Participants from both groups, students and teachers, had some experience in technologies application. Teachers of our university often use distant courses and online platforms for interactive learning (Learning apps), for assessment (Google classroom, Classtime), audio and video content to bring authenticity to the classroom. Students often enroll in field-related MOOC courses, watch open lectures and participate in interdisciplinary collaborative projects using online platforms (NewComment, Padlet, etc).

The questionnaires were given at the end of the term (4 months of studying). Students were informed of the purpose and process of the study, their participation was voluntary. If they wanted to discontinue participation in the study, students could stop it without any academic consequences. The study was approved by the scientific review committee of the Department of the Linguistics at Igor Sikorsky Kyiv Polytechnic Institute.

\subsection{Research Instruments and Procedure}

With a view of data collecting, we designed an evidence-based questionnaire but differentiated questions for students and teachers for the better perception of the question content. The questionnaire was suggested at the end of the term during which teachers suggested students using educational mobile technologies to perform SDL 
activities out of classes. As teachers knew the nature of SDL, clearly understood the necessity of its formation and had from 3 to 5 years of technology application experience, we decided to suggest a short version of the questionnaire:

1. What are the strengths, weaknesses, opportunities, and threats of SDL formation by means of educational technologies?

2. What improvements can you recommend to eradicate the weaknesses and improve the strength?

3. How do you deal with media literacy to help students find reliable sources?

4. How do you assess students if they go beyond the curriculum or material you suggest?

Students were informed of the nature of SDL and we explained the purpose of some strategies, technologies, and changes we introduced into the traditional ESP course. As students' answers were considered as essential for our research, we extended the questionnaire and organized it by distribution questions into three parts: SDL and technology integration experience; understanding of self-directed learning nature and a SWOT analysis of technologies application:

\section{Experience:}

1. What educational technologies have you ever worked with?

2. Have you ever experienced and completed any MOOC courses?

3. Why did you decide to study on your own? (If you answered yes to 1 and 2questions )

4. What knowledge or skills did you master (write some variants)? (If you answered yes to 1 and 2questions )

SDL understanding:

1. What are your learning needs?

2. What do you do if you feel a necessity to learn something more ?

3. Are you completely or partially satisfied with the material suggested by the curriculum and teachers?

4. Do you think it is a waste of time to learn something more on your own because teachers know what volume of information is enough for you?

5. If you learn on your own, how do you understand that you did it well and it is enough for you or you need more effort or resources?

SWOT analysis:

1. What are the benefits of educational technologies if you want to continue your study without a teacher? (Strength)

2. What challenges did you encounter while self-studying assisted with educational technologies? (weaknesses)

3. What would you like to change to make self-studying via technologies more appropriate? (Threats)
4. How do technologies help you become an independent learner? (Opportunities)

\subsection{Data Analysis}

Comparing the results of two questionnaires allows us to reflect on weaknesses and threats and suggest possible solutions to some problems of SDL formation from the perspective of its optimization for teachers and students as equal partners of the educational process. The SWOT analysis was applied to collect the data and analyze it in terms of strengths, weaknesses, opportunities, and threats of the observed process. In our qualitative study participant's responses were analyzed through the content analysis and inductive approach to reveal constraints and limitations of the study. Content analys is is a valuable tool to reveal the audience trends and concepts and it bridges the gap between quantitative and qualitative methods. As a content analysis unit, we took 25 key concepts as "self-paced learning", "autonomous learning", "online tools", "distant learning", "educational technologies", "mobile technologies", "credibility", "feedback", "interactive learning", "digital safety" and their synonyms We analyzed the frequency of their usage with the positive or negative connotations. Moreover, content analys is implies categorization to identify homogeneous groups and it helps categorize the participants' answers into groups The inductive approach allowed developing conclusions from collected data by analyzing the texts of interviews, thus, we moved from specific data to general conclusions.

\section{Results}

As the key objective of our research is a SWOT analysis, we would like to display the results of this part of the questionnaire first (teachers' questions 1 and 2, students' questions from the part: SWOT analysis). The teachers' and students' answers did not differ much as students and teachers are partners in the education process. However, some discrepancies should be taken into consideration.

First, we would like to represent the results of the students' questionnaire. Students had to answer four open-ended questions; fro $m$ these ans wers we could c learly identify strengths, opportunities, weaknesses, and threats of SDL development through educational technologies. Answers to the first question was considered as strengths and the fourth covered opportunities, the second question was about weaknesses and the third question was related as threats:

Strengths: a wide variety of resources choice, the possibility to study at own pace and at any place, tasks relevant to knowledge level and gradual complication of tasks, reduction of boring written home tasks and exerc ises, flexibility, immediate feedback, absence of subjective as ses sment. 
Weaknesses: some resources are paid, a great nu mber of not credible resources, partial autonomy because of not clear or not appropriate tasks instructions, feedback without explanation of mistakes;

Opportunities: international global community, interactive learning environment, understanding of students needs and interests, increasing motivation to study;

Threats: digital safety, inadequate self-assessment and self-reflection due to lack of theses skills development, insufficient knowledge of information quality assessment.

Regarding teachers' answers, we obtained answers not only in terms of SWOT analysis but with suggested practical recommendations on problematic issues eradication. The answers to the first question are as follows:

Strengths : finding "common language" with "digitally native" students; personalization of learning according to students needs, interests, background and learning styles; flexibility; diversity of methods and forms of learning; knowledge level adjustment; high level of interactivity; the rise of students' self-confidence and motivation to learn.

Weaknesses: the credibility of resources; lack of tasks that promote situative learning and unattainable character of some instructions; continuously changing technologies; price; problems with access;

Opportunities: digital competence enhancement; development of self- reflection and self- organization skills;

Threats: more development for digital than academic competence; lack of teachers' training on a comb ination of pedagogy and technologies; lack of quality standards of e-learning programs and poor level of quality control.

Among the strategies suggested for problematic issues solutions, we found the followings: to create a separate learning module on information and resources quality assessment; to pay more attention to self-reflection skills; to develop self-directed learning culture as a learning continuum environment; to assess readiness to self-learning prior to proposing SDL activities.

In order to develop meaningful recommendations, we chose common characteristics that we encountered in students' as well as teachers' answers. By analyzing common responses we were able to suggest a holistic approach to the solution of some problems. However, common answers were about strengths and weaknesses, opportunities and threats were seen in a different way. Among common answers we would like to mention:

Strengths: flexibility, variety of forms and methods, relevance to students' background and needs;

Weaknesses: cost, the credibility of resources.

In our mind, opportunities and threats are more holistic characteristics that predict the development of the phenomenon and analysis of these criteria requires more experience and background knowledge.

Regarding question 3 from the teachers' questionnaire, we obtained the following answers: I give the list of resources chosen by myself $(n=14)$; I suggest only MOOCs or scientific articles $(n=11)$; I explain how to find reliable sources $(n=5)$. The majority of teachers said that they appreciated students' curiosity and motivated students to learn more by giving more positive as ses sment.

The results of a SWOT analysis would not be objective and reliable if students did not have any experience with educational technologies application. Thus, we included this part into the questionnaire and received the answers: question 1- I have used educational web sites, YouTube, Ted-talks, MOOCs and open lectures from other universities $(\mathrm{n}=85)$; question 2- I completed a MOOC course $(n=11)$; question 3- I wanted to get more information $(n=57)$; I missed the lecture $(n=15)$; I do not like the way a teacher de livers the course (13); question 4mostly grammar (considering English) $(\mathrm{n}=83)$, professional information $(\mathrm{n}=80)$; knowledge beyond the curriculum $(n=27)$.

Among learning needs students specified media literacy $(n=33)$; field-related knowledge $(n=93)$; the English language knowledge $(\mathrm{n}=78)$; self-learning strategies $(n=53)$; some students did not answer the question $(n=29)$. Answering the second question from the part about SDL, students mentioned: I search on the Internet $(n=87)$ and I ask a teacher, a friend or parents $(n=15)$. The results of the third question were: I am completely satisfied $(n=42)$; I am partially satisfied $(n=50)$ and I am not satis fied $(n=10)$. The majority of students answered that they did not consider additional studying as a waste of time $(n=78)$ and the rest of the students said that they trusted the educational experts who developed the curriculum. The answers to the fifth question were: if I have no more questions and can explain it to my friend $(n=37)$; if I pass a test or exam successfully $(n=46)$; if I can practically apply my knowledge $(n=19)$.

\section{Discussion}

The integration of SDL formation strategies into the English for Specific Purposes (ESP) course was conditioned by the necessity to equip students with SDL skills to help them organize their future professional career and adapt to constantly changing labor market demands. SDL is considered to be a soft skill that can be easily integrated into the language learning course as well as other soft skills as communication, cooperation, critical thinking, and media literacy [20]. The language teaching process also suggests students' self- learning tasks to master knowledge or revise rules. Thus, we considered it relevant to enhance students' skills of SDL while the language learning due to such SDL features as flexibility, personalization, adjustment to knowledge level, high level of intrinsic motivation and self-discipline. 
SDL is characterized by its high level of flexibility that enables students to choose what they want to master or revise at their own pace. It provides students with self-planning skills of the learning process and knowledge level adjustment.

So, ESP teachers identified students' language problems and prioritized the $\mathrm{m}$. Those defined as primary ones were mastered under teacher's control, but other learning gaps were suggested for students for self-learning allowing students to chose how and when to master them but with following teachers' control. For example, we often suggest online platform Agendaweb where students can find exerc ises on any language topic and language level. When it comes to reflection, we use activities that teach students to as sess outcomes: journaling, blog writing, online group collaboration projects when peers can reflect on personal views and mistakes [21].

Today's technologies are of great assistance in facilitating students in this educational endeavor. However, SDL requires a high level of digital co mpetence and critical thinking for information assessment. It is especially important when students express an interest in particular topic but they do not know where to find the information or reliable educational resource. As we noticed from the results of the questionnaire, teachers prefer giving students lists or resources considered by teachers themselves as reliable. So me teachers suggest a platform or resources and explain how to validate its authenticity and accuracy to develop the skills of information assessment and media literacy. Unfortunately, not all teachers have enough time or knowledge to teach students media literacy and teachers expressed their concern about this is sue. However, they understand that successful self-practice of new information and opportunities discovery increases students' motivation, awareness of self-interest and expands the limits defined by the curriculum
Students' answers regarding their experience of technologies usage allow us to assume that students' opinion about strengths and weaknesses are objective and evidenced-based. The reasons to employ SDL are meaningful and rather predictable as engineers should be curious and think critically to find solutions to problems. However, rather unpredictably we found answers about not acceptable teaching methods that forced students to learn themselves. We did not suppose that this fact could be a reason for SDL, but it was rather an exceptional point of view.

Speaking about SDL awareness and readiness, we have to admit that the level of students' understanding of SDL is rather primitive. As a unique source for information they consider the Internet, but they do not know exactly how to find the necessary information and how to asses it. Another problem is a lack of knowledge about self-learning strategies, information memorizing and processing, assessment of self-learning results and achievements. Teachers have to pay attention to this is sue and integrate some SDL strategies into class activities. But despite these problems, we observed a positive is sue that students can identify their learning needs and consider SDL as a beneficial tool for academic achievement improvement as well as for career development. And efficient mobile technologies can be a trigger for students to master their SDL skills and accept the concept of lifelong learning.

Since we are ourselves ESP teachers and the majority of teachers who participated in the study were ESP teachers, we chose some skills necessary for becoming a successful self-directed learner and tried to develop these skills through ESP activities assisted by educational technologies. SDL develop ment requires more skills to master but not all of them can be integrated into the ESP context. In Table 1, we demonstrate the possible solutions to how to combine the SDL skills formation and language learning context.

Table 1. SDL skills formation via ESP activities assisted with mobile technologies

\begin{tabular}{|l|l|l|}
\hline SDL skill & Meaning & ESP activities \\
\hline Basic skills & Language literacy and digital literacy & $\begin{array}{l}\text { Educational videos and e-books, online testers to drill grammar } \\
\text { rules }\end{array}$ \\
\hline Autonomy & Self-reliance, initiative, resourcefulness & $\begin{array}{l}\text { Researchijng the topic of interest (Agendaweb, Engvid) and } \\
\text { shareing the information and experience }\end{array}$ \\
\hline Learning skills & $\begin{array}{l}\text { Time-management, understanding assignment } \\
\text { instructions, organization of material, planning } \\
\text { the learning process, responsibility for outcomes }\end{array}$ & $\begin{array}{l}\text { Web-quests on language topics, field-related topics } \\
\text { presentation, MOOC, note-taking techniques development }\end{array}$ \\
\hline $\begin{array}{l}\text { Problem } \\
\text { development skills }\end{array}$ & $\begin{array}{l}\text { Designing strategies for meet ing learning } \\
\text { outcomes, critical and creative thinking }\end{array}$ & $\begin{array}{l}\text { Cooperative online projects (ThingLink, Tour creat or, Answer } \\
\text { Garden, Padlet), creating web-sites, concept mapping }\end{array}$ \\
\hline $\begin{array}{l}\text { Self-assessment } \\
\text { skills }\end{array}$ & $\begin{array}{l}\text { Self-reflection, analyzing, awareness of } \\
\text { self-interests and abilities }\end{array}$ & Journaling, blogs, e-portfolio, learning contract \\
\hline
\end{tabular}


Considering the results of students' and teachers' questionnaires, we should keep in mind that they have a lot of common points, such as flexibility and mobility, interactivity, variety of methods and forms, not credible resources, etc. Therefore, we would like to focus on different points as it will allow us to substantiate some recommendations on improvement.

Among different points from the strengths, students $(53 \%)$ pointed out the absence of subjective unclear assessment. It is obvious, that educational technologies employ an exact and clear set of assessment criteria for a learner whereas teachers sometimes might be more loyal or strict to students due to human factors or personal attitudes. However, teachers' loyalty might be useful to encourage or to stimulate students to focus on progress. But some students are shy of their mistakes and do not want to be judged only by a teacher. Nevertheless, students (87\%) appreciate immediate feedback that teachers sometimes cannot provide due to lack of time, big academic groups or much workload.

Teachers and students understand weaknesses in a different way. Students (93\%) mostly paid attention to the price and user-friendly operation mode of the technology; however, teachers $(88 \%)$ paid attention to the necessity of continuously updating the platforms of programs and universality of task instructions. It means that there is no variability of tasks in terms of one platform of technology, and it is impossible to change the instruction according to students' needs. Sometimes we had to change the technology or platform to satisfy some specific learner's needs or learning style.However, tasks and educational material suited well to the majority of students. Unfortunately, technologies occasionally become "unindividualized". Such situations create a phenomenon known as partial autonomy that students should apply to teachers in order to find other technology, to find an explanation or to alter the instruction.

Some students $(37 \%)$ confes sed that they were afraid to enter SDL since our traditional classes were teacher-centered and students could not organize the learning alone. But with the gradual connection of SDL activities with technologies, this process goes easier as students become independent learners at classes under the teachers' supervision. One drawback of many educational technologies is that they do not provide an explanation for mistakes but rather give a general score of mistakes. So students need much time to find out the causes of mistakes and often drop out of the learning because of repeating the same mistakes. Also, insufficient self-reflection skills impact this process.

One of the threats that teachers $(62 \%)$ admitted was the shift from academic competence improvement to mere digital competence enhancement. When students are captured by the visual effects of the technology, friendly user interface or technology itself, they might forget about learning outcomes and study the digital processes of a resource. Such distraction can be prevented by facilitating students' goal-setting skills and a clear and feasible plan of learning designed according to students' needs and possibilities. The results of our study are in a line with Howland et al. [6] who considered digital technologies as cognitive tools that enhanced students' abilities to determine and express their internal cognitive processes when students learn with the tools, rather than from the tools.

A meaningful and efficient method of SDL training is flipped classes which are implemented at our university. By means of such technologies as Google classroom, Socratics, LearningApps, Quizlett teachers develop tasks for self-learning so that students from the first course are us ed to complete some tasks independently with automated feedback but with a topic determined by teachers. During the academic year, students perform a lot of individual and team projects that also facilitate SDL development by teaching how to solve problems and search for information. In this case, the topics for the project and strategy are chosen by students but feedback is given by teachers, peers or a jury. We use such technologies as web quests, Tour creators, website constructors, Prezzi, Thinglink, etc. With the project completion students are able to monitor the plan of the performance, change goals, manage their time and strategies, thus, to train all those skills necessary for a future adult career. [22] Such technologies as Evernote, Padlet, and Mindmeister enhance students' self-management skills by structuring and visualizing their ideas, finding hidden perspectives and threats, collecting resources and citations, revising and re-panning strategies.

The results of the present survey also point out the problem of self-reflection skills formation to become successful independent learners [17]. We suggest students such technologies as LiveJournal, Blogger (written and audio versions), and Twitter. While working with these tools, learners write their reflections, analyze mistakes and results, add videos or audio recordings and teachers or peers can comment, give advice or share experience that will support continuous learning through community intelligence [23]. However, the most meaningful tool for self- reflection is a platform ePortfolio that gives templates, us efultips and structure on how to organize the evidence of their academic achievements.

In the summary of our research we would like to share with some recommendations on how to facilitate SDL through educational technologies and prevent threats and weaknesses:

1. Design a curricular of the academic discipline including some SDL activities and let students choose technologies to use, topics to discuss, strategies to complete tasks and even design of the tasks according to their learning gaps;

2. Train students goal-setting and self-managing skills while performing in-class activities before giving them tasks to complete alone, articulate educational 
goals of in-class activities and accompany the performance of the activity with comments on strategies how to achieve better results ;

3. Design activities to connect students prior knowledge with new concepts in such a way that students could understand what gaps they have to master;

4. Choose those technologies that provide meaningful immediate feedback;

5. Create a separate academic module to equip students with knowledge about internet safety, information and resources quality assessment;

6. Provide access to technologies in and out of the class and suggest the list of credible recommended resources;

7. Choose technologies taking into account the abilities and interests of students;

8. Provide space for self-reflection and connect students' success made beyond the class with greater academic goals;

9. Create a foru mor a chat network to exchange ideas or share the experience;

10. Build a co-operative supportive learning environment and serve as a facilitator rather than an instructor.

\section{Research Limitations}

However, some limitations should be mentioned. The study was carried out at Igor Sikorsky Kyiv Polytechnic Institute, so the results are not general to other technical universities. The evidence for the research was taken from one subject English for Engineering. Therefore, considering field-related courses, the practical recommendations might vary. The participation was voluntary and optional, so some more motivated students did not take part in the study, thus, there could be a bias in the results.

\section{Conclusions}

Our study represented some reflections on university strategic SDL manage ment using SWOT analysis. For each point of the analysis, we generated sets of appropriate activities and technologies to reduce and eliminate weaknesses or threats as well as facilitate strengths, starting with changing perceptions and attitudes of teachers and students towards SDL and educational technologies. Psychological and pedagogical dimensions of this process should be taken into account and technology must be adapted according to the learning needs, interests and background to respond and respect the educational endeavor of every participant of the learning process. These findings provide the following insights for future research: conducting a similar study among students of other faculties: information technologies, humanities, economics. Students' focus on SWOT features might differ depending on the field they major in. Further work needs to be done to establish a connection between students' SDL readiness level and perception of technologies integrated into the learning process. A greater focus on media literacy teaching could produce meaningful findings that account more for SDL development via mobile- assisted strategies.

\section{REFERENCES}

[1] Brookfield, S. D. Powerful Techniques for Teaching Adults. CA: John Wiley, San Francisco, 2013.

[2] Knowles, M., Holton III, E., \& Swanson, R. The Adult Learner: The Definitive Classic in Adult Education and Human Resource Development. San Diego, CA: Elsevier, 1998

[3] Hiemstra, R., \& Brockett, R. G. Reframing the Meaning of Self-Directed Learning: An Updated Model, Proceedings of the 54th Annual Adult Education Research Conference, NY: Saratoga Spring, 2012

[4] Gökçearslan, Ş. Perspectives of Students on Acceptance of Tablets and Self-directed Learning with Technology. Contemporary Educational Technology, Vol. 8, 40-55, 2017. Online available from: https://www.researchgate.net/ publication/312489565_Perspectives_of_Students_on_Acc eptance_of_Tablets_and_Self- directed_Learning_with_Te chnology

[5] Tan, L., \& Koh, J. H. Self-Directed Learning: Learning in the 21st Century. Singapore: Ministry of Education, 2014.

[6] Howland, J., Jonassen, D., \& Marra, R. M. Meaningful learning with technology (4th ed.). Boston, MA: Allyn \& Bacon, 2012.

[7] Kim, R., Olfman, L., Ryan, T., \& Eryilmaz, E. Leveraging a personalized system to improve self-directed learning in online educational environments. Computers \& Education, Vol. 70, 150-160, 2014. DOI: 10.1016/j.compedu.2013.08. 006

[8] Doyle, T. Helping Students Learn in a Learner-Centered Environment. A Guide to Facilitating Learning in Higher Education. VA: Stylus, Sterling., 2014

[9] Ambrose, S., Brid ges, M., DiPietro, M., Lovett, M., Norman, M. How Learning Works: Seven Research-Based Principles for Smart Teaching. Mayer San Francisco: Jossey-Bass, 2010.

[10] Wang, M. T., \& Holcombe, R. Adolescents' Perceptions of School Environment, Engagement, and Academic Achievement in Middle School. American Educational Research Journal, Vol. 47, 633-662, 2010. DOI: $10.3102 \% 2 \mathrm{~F} 0002831209361209$

[11] Zimmerman, B. (2008). Investigating Self-Regulation and Motivation: Historical Background, Methodological Developments, and Future Prospects. American Educational Research Journal. Vol. 45, 166-183, 2008. DOI: 10.3102/0002831207312909. 
[12] Toit-Brits, C. \& Zyl, C.. Self-directed learning characteristics: making learning personal, empowering and successful. Africa Education Review. Vol.14, 1-20, 2017. DOI:10.1080/18146627.2016.1267576.

[13] Grover, K., Kacirek, K., Miller, M. How Learners Respond to a Lack of Information. Proceedings of the Adult Education Research Conference: The Intersection of Self-Directed Learning, Communities of Practice, and Social Networking:. Kansas State University Libraries: New

Prairie Press, 2013. Online av ailable from: https://newprair iepress.org/cgi/viewcontent .c gi ?article $=2970 \&$ context $=$ aer c

[14] Tekkol, İ. A., \& Demirel, M. An Investigation of Self-Directed Learning Skills of Undergraduate Students. Frontiers in psychology. Vol. 9, 23-34, 2018. DOI: 10.338 9/fpsyg.2018.02324

[15] Garrison, D. R. Self-directed learning: Toward a comprehensive model. Adult Education Quarterly. Vol. 48, 18-33, 1997. DOI: 10.1177/074171369704800103

[16] Candy P. C., Crebert G., O'Leary J. Developing Lifelong Learners throu gh Undergraduate Edu cation. National Board of Employment, Education and Training, Report no 28. Canberra: Australian Government Publishing Service, 1994.

[17] Haidari, S, Yanpar Yelken, T , Akay, C. Technology-enhanced Self-directed Language Learning Behaviors of EFL Student Teachers. Contemporary Educational

Technology. Vol. 10, No. 3 , 229-245. 2019. DOI: 10.3093 5/cet.590003

[18] Dyson, R.G. Strategic development and SWOT analysis at the University of Warwick. European Journal Operational Research, Vol. 152, No. 3, 631-640, 2004. DOI: 10.1016/S 0377-2217(03)00062-6

[19] Creswell, J. W. Research design: Qualitative, quantitative and mixed methods approach. SAGE, 2014.

[20] Hawkins, M. Self-directed learning as related to learning strategies, self-regulation, and autonomy in an English language program: A local application with global implications. Studies in Second Language Learning and Teaching. Vol. 8, 445-469, 2018. DOI: 10.14746/ssllt.2018 .8.2.12.

[21] Lavrysh, Y. Peer and self-assessment at ESP classes: case-study. Advanced Education. Vol. 6, 60-68, 2016. DOI: 10/20535/2410-8286.85351

[22] Lytovchenko, I., \& Saienko, N. Structural models of corporate universities in the United States of America. The Revista Amazonia Investiga. Vol. 8, No. 24, 225-230, 2019.

[23] Jenkins, H. Confronting the Challenges of Participatory Culture: Media Education for the 21st Century. Chicago: The MacArthur Foundation, 2006. 